\title{
The Role of Employee Behaviour and Organizational Structure in the Relationship Between Strategic Planning and Competitive Advantage of Large Manufacturing Firms in Kenya
}

\author{
Jackson K. Maingi ${ }^{1}$, Zachary B. Awino ${ }^{1}$, Peter O. K'Obonyo ${ }^{1} \&$ Ganesh P. Pokhariyal ${ }^{2}$ \\ ${ }^{1}$ School of Business, University of Nairobi, GPO Nairobi, Kenya \\ ${ }^{2}$ School of Mathematics, University of Nairobi, GPO Nairobi, Kenya \\ Correspondence: Jackson Maingi, School of Buisness, University of Nairobi, P.O Box 30197, GPO Nairobi, Kenya \\ Tel: 254-722-527-877.
}

Received: March 3, 2019

Accepted: March 25, 2019

Online Published: March 27, 2019

doi:10.5430/jms.v10n3p1

URL: https://doi.org/10.5430/jms.v10n3p1

\begin{abstract}
Several studies have been carried out in the past to find out how strategic planning and competitive advantage are connected and the causes of differences in competitive advantage among firms. Scholars have argued that competitive advantage can emanate from either internal or external sources and is usually in several forms which include; valuable resources, the position held within the industry, position within the marketplace, operating at lower costs than rival firms, differentiation, capabilities and dynamic capabilities. This study sought to advance knowledge and was based on the premise that strategic planning influences competitive advantage both directly and also indirectly by way of the mediating influence of employee behaviour and the moderating effect of organizational structure. The study was underpinned by the competitive advantage typology/theory, the resource-based theory, dynamic capabilities theory, goal-setting theory and contingency theory. The study used a positivist research paradigm and a cross-sectional survey design. Data collected from 122 large manufacturing firms was analyzed using both descriptive and inferential statistics. Hypotheses were tested using both simple and multivariate regression analysis as well as hierarchical analysis for mediating and moderating effects. The findings indicate that overall strategic planning has a statistically significant influence on competitive advantage and that employee behaviour completely mediates the relationship between strategic planning and competitive advantage while organizational structure has a partial moderating effect between strategic planning and competitive advantage. In addition, the joint influence of employee behaviour and organizational structure is different from the influence of individual variables on the relationship between strategic planning and competitive advantage. The outcomes from this research lend support to previous enquiries and support all the theories used to underpin the study.
\end{abstract}

Keywords: strategic planning, competitive advantage, employee behaviour, organizational structure, lower costs, differentiation, capabilities, dynamic capabilities

\section{Introduction}

There is no single explanation as to why firms attain competitive advantage and therefore different concepts have been used to explain the causes. The type of business level strategy applied, either low cost or differentiation, can generate competitive advantage (Porter, 1980, p. 35). A different conceptual foundation that focusses more on "capabilities of the firm states that a firm's ability to achieve and sustain competitive advantage is directly related to its firm-specific resources (Barney, 1991, p. 105; Peteraf, 1993, p. 189; Rumelt, 1984, p. 561; Wernerfelt, 1984, p. 171)." Hamel and Prahalad (1994) have argued that know-how, knowledge, intellectual assets and competencies are the key drivers of competitive advantage and as a result superior performance. Hamel and Prahalad (1994), agree with Pfeffer (1994) who has isolated human resources practices including organizational structure as the main driver of competitive advantage.

In most of the previous studies cited by the researcher, nearly all the elements contributing to competitive advantage have been studied in isolation or in some combination. "Mutunga and Minja (2014, p. 1) studied the generic strategies employed by Food and Beverage firms in Kenya and their effects on competitive advantage and established a positive relationship." Gowrie, Sreenivasan and Govindan (2012, p. 29) studied "the critical success 
factors of sustainable competitive advantage of manufacturing firms in Malaysia and established the factors including cost leadership and differentiation.” Dirisu, Iyiola \& Ibidunni (2013, p. 258) studied product differentiation as a tool of competitive advantage on the Unilever firm in Nigeria and found a positive relationship. The reviewed empirical literature indicates conceptual gaps because the studies cited so far did not consider how the strategic planning and competitive advantage relationship is influenced by employee behaviour and organizational structure.

Studies to establish causes of competitive advantage have been done under various contexts. A study between "strategic planning and competitive advantage in Kenya's ICT Small and Medium Enterprises (SMEs) sector" (Awino, 2013, p. 191) was carried out and a positive relationship established. Mutunga and Minja (2014, p. 1) carried out their study on "generic strategies employed by the Food and beverage sector in Kenya's manufacturing industry and established a positive relationship." Dirisu et al. (2013) carried out their study on one manufacturing firm, Unilever PLC Nigeria and established the existence of a positive influence of product differentiation on organizational performance. Gowrie et al. (2012) carried out their study on manufacturing firms as a whole in Malaysia. They did not distinguish between small, medium-sized or large firms. Chavunduka, Chimunhu \& Sifie (2015, p. 12) carried out a study on the "intensity of strategic planning and how it affects the performance of a firm using the case of Zimbabwe Mining Development Corporation and found a positive relationship." Kumar (2015, p. 64) carried out "a study on the correlation between strategic planning and firm performance based on European, Asian and American firms in India and found a positive association between strategic planning and performance regardless of size of the firm." Flamholtz and Hua (2010, p. 222)) carried out a study in the USA "on searching for competitive advantage in the black box and established a positive relationship between organizational development factors and competitive advantage.

There seems to be contextual gaps between the empirical studies cited by the researcher and this study. Firstly, the researcher has not come across a similar or nearly similar study to the one being studied that has been carried out on large manufacturing firms in Kenya. Secondly, the context for the current study is all large manufacturing firms in Kenya as per the Kenya Association of Manufacturers (KAM) 2015 Directory. Most of the other contexts studied were different and included the ICT sector in Kenya, food and beverage sector in Kenya, case study of one firm in Nigeria and other contexts in far off countries including the USA, India and Malaysia.

As for the methodology used in some of the empirical literature reviewed; Awino (2013), Mutunga and Minja (2014), Gowrie et al. (2012), Awino (2007) and Manar (2014) used descriptive cross sectional surveys and on large samples. This same methodology was applied under the current study. On the other hand, Dirisu et al. (2013) used a case study of one firm, Flamholtz and Hua (2010) sampled sixteen companies drawn from eight industries while Cees, Van R, Guido and Majorie (2009) collected their data from three (3) large companies via on-line surveys. All the scholars noted studied different topics from the one being studied and therefore, even for the scholars who had cross sectional surveys as their methodology, there still exists methodological gaps because of the subject of study.

As demonstrated, there remained unresolved issues along the conceptual, contextual and methodological spheres in the relationship among the variables being studied. The current study was on strategic planning being the predictor variable while competitive advantage was taken as the outcome variable. At the same time, employee behaviour was taken as the mediating variable while organizational structure was taken as the moderating variable. The researcher has not identified a similar study undertaken that has considered the three variables so far in the literature reviewed and even from the empirical studies documented. Most contexts of the studies nearer the one undertaken were from far away countries. This study addressed the gaps identified from the literature reviewed and attempted to answer the question: Is the relationship between strategic planning and competitive advantage of large manufacturing firms in Kenya influenced by employee behaviour and organizational structure?

The overall objective of the study was to determine whether the relationship between strategic planning and competitive advantage of large manufacturing firms is influenced by employee behaviour and organizational structure. The specific objectives were to:

(i) Determine the influence of strategic planning on the competitive advantage of large manufacturing firms in Kenya.

(ii) Determine the influence of employee behaviour on the relationship between strategic planning and competitive advantage of large manufacturing firms in Kenya.

(iii) Establish the effect of organizational structure on the relationship between strategic planning and competitive advantage of large manufacturing firms in Kenya. 
(iv) Establish the joint influence of employee behaviour and organizational structure on the relationship between strategic planning and competitive advantage of large manufacturing firms in Kenya.

\subsection{Materials}

The study to establish the influence of employee behaviour and organizational structure on the relationship between strategic planning and competitive advantage of large manufacturing firms in Kenya was anchored on various theories. Michael Porter's typology (theory) was the main theory. The other supporting theories included the Goal-setting theory which underpins employee behaviour, contingency theory which underpins organizational structure, resource-based theory (RBT) and dynamic capabilities theory (DCT) which underpin competitive advantage (Barney, 1991, p. 99; Teece, Pisano \& Shuen., 1997, p. 509) and to some extent, employee behaviour and organizational structure concepts.

The theory of competitive advantage by Porter (1990, p. 34) "proposes that states and businesses need to pursue policies that create goods of high quality for sale at high prices in the market. The competitive strategy is concerned with taking offensive and defensive actions that lead to the creation of a defendable position in an industry in order to cope successfully with competitive forces and create a superior return on investment." Porter (1990) argues that the foundation for above-average performance within an industry is sustainable competitive advantage. Two ways of achieving competitive advantage have been identified; one is through cost leadership and the other is through differentiation.

Porter's competitive advantage theory has been criticized for the confusion between firms and nations. It has also been said that the theory is characterized by an environmental determinism and a linear cartesian point of view towards complex problems. This orientation assumes an enterprise is just the sum of its parts rather than being a complex, uncertain and ever-changing relationship amidst its parts. Beyond these criticisms, the theory of competitive advantage still stands strong. This study proposed that a firm can select a firm-level strategy like low cost or differentiation at the strategic planning stage. This firm-level strategy would lead to a review of the organizational structure. Once a structure that is suitable to employees is selected, the firm is in a position, by applying the selected firm-level strategy, to work towards attaining a sustainable competitive advantage position.

"Goal-setting theory (Locke and Latham, 1990, 2002, p. 705) was developed in an inductive manner within the industrial/organizational (I/O) psychology in over a period of 25 years. It was founded on 400 laboratory and field studies. These studies indicated that some specific and high or hard goals invariably lead to higher levels of task performance than do easy, unclear or abstract goals including the exhortation to individuals to do their best." If an individual is "committed to the goal, has the required capability to achieve it and does not have other conflicting goals, then there exists a positive, linear relationship between goal difficulty and the performance of the task" (Yearta, Maitlis \& Briner, 1995, p. 238). Due to the fact that goals refer to future valued results, goal setting becomes primarily a discrepancy creating process. It involves dissatisfaction with an individual's current condition and the longing to achieve an objective or result.

Goal setting has faced several criticisms. "The very strong concentration on the goals that are set makes individuals fail to notice a striking component of their visual world" (Bazerman and Chugh, 2006, p. 88). With goals, individuals limit their focus and this limiting or narrowing effect can blind individuals to significant matters that do not appear related to their goal, and yet such matters may be important in accomplishing the task. "The inclination to focus too narrowly on goals gets even worse when managers choose the wrong course by setting the wrong goals. It has also been argued that goal setting can distort risk preferences" (Neale and Bazerman., 1985, p. 19).

"Goal setting can bring about behaviour, which is unethical (Barsky, 2007, p. 63)). One study carried out tried to establish a direct connection between goal setting and not telling the truth. In this study, it was found out that participants were more likely to misrepresent what their performance was or even cheat when they were faced with a specific challenging goal, than when they were not." This was more the case "when their actual performance level just fell a bit short of attaining the set goal" (Schweitzer, Ordonez and Duma, 2004, p. 422). Goal setting can impede learning (Wood, Bandura and Bailey, 1990; Locke and Latham, 2002). "Whereas goal setting can increase extrinsic motivation, yet it can also hurt intrinsic motivation if an individual gets involved in a task just for the sake of it" (Rawsthorne \& Elliot, 1999, p. 181). The criticisms of goal-setting theory notwithstanding, the theory has withstood the test of time and its applicability is still strong.

The criticisms noted notwithstanding, this study agrees with the implications of goal setting by Locke and Latham (1990, p. 706) and suggests that at the strategic planning stage, "firstly, clear-cut goals should be established and put in place to direct behaviour and maintain the individual's motivation. Secondly, the goals that have been set should 
be challenging enough but also set at realistic levels, and thirdly, there should be accurate, complete and timely feedback recognizing that knowledge of outcomes is usually linked to high performance."

The contingency theory is founded on the presumption that there is no one form of organizational structure, which can be applied equally to different types of organizations. Instead, how effective an organization is depends on a fit between the technology use, its information system, the volatility of the environment, the organization size and the components of the organizational structure. Van de Ven and Drazin (1985, p. 333) "have explained the idea of fit in three different ways, that is, selection, interaction and systems approaches." Once a fit is obtained between strategy and structure, the firm will be in a position to work towards attaining sustainable competitive advantage. During the time the firm is reviewing and changing its structure, it will have to ensure the type of structure selected can enable employees to adopt a strategically aligned behaviour and that they will be motivated and committed to work towards attaining the goals and objectives set out. Contingency theory can be used to support the organizational structure variable.

The basic research problem of contingency theory is that it is inherently dynamic. This is in spite of the concepts of fit used in actual research being not dynamic but static. Based on classical comparative studies, the concepts of fit presuppose a balanced or equilibrium position in both time and space. This equilibrium position has left a lacuna between applied ontology in contingency theory research and an ontology that is required for explaining the research problem. This study proposes that after a firm has determined the strategy to follow at the strategic planning stage, thereafter it will have to review and change its structure in order to align it to the new strategy.

According to Peteraf and Barney (2003, p. 309), "an organization will achieve a competitive advantage position when it generates additional economic benefit than its competitors in its product market. The RBT is based on two foundational assumptions about organization-based resources to clarify how sustained competitive advantage is generated" (Peteraf \& Barney, 2003, p. 309). The first assumption is that organizations own bundles of resources, which are different even when they are operating within a similar industry. The second assumption is that the resource differences may be sustained for a while due to the difficulty of buying and selling of resources across organizations.

This difficulty in trading makes it possible for benefits from diverse resources to be sustained over a period of time (Barney \& Hesterly, 2012). Four conditions have to be simultaneously met for sustained competitive advantage (SCA) to exist and these are; the resources have to be Valuable, Rare, inimitable and there should be good Organization (VRIO framework). An organization must be well organized in order to utilize the maximum competitive potential of the resources and capabilities it possesses (Barney \& Hesterly, 2012).

Some criticisms have been levelled against the RBT. For example, methodological challenges keep occurring in the RBT literature. A pivotal matter that arises is how to measure resources mainly because a number of them are of an intangible nature (Godfrey \& Hill, 1995). Molloy, Chadwick, Ployhart and Golden (2011) have picked up on the theoretical disconnect existing between RBT and the measuring of intangible resources and argued that this disconnect leaves some key questions un-addressed. This disconnect further undermines confidence in empirical tests that are supposed to support RBT and narrows the usefulness of future research. Molloy et al. (2011) have identified the gap through a content analysis of how scholars studied 186 intangibles in tests of RBT, which have recently been established.

This study posits that unique resources owned by the firm can be configured and used in a way that enables the firm to attain a competitive advantage position. It must be pointed out that the behaviour of employees will play a crucial role in the way the resources are configured and deployed if the firm is to attain and even sustain a competitive advantage position.

The Dynamic Capabilities Theory (DCT) is an extension of RBV and RBT (Teece et al., 1997, p. 509). It underscores the deployment of the capabilities of the organization so as to attain higher-level performance. Dynamic capabilities (Teece et al., 1997, p. 509) "emphasize two main facets. The first facet is dynamic, which reflects the ability to have competencies renewed in order to agree with changes occurring in the business environment." The second facet is capabilities, which emphasizes the crucial part played by strategic management in making organizations "to adapt, integrate and redesign internal and external organizational skills, resources and practical competencies" (Teece et al., 1997, p. 509). All this is done in order to counter the effects of an environment that is fast changing.

"In spite of the extensive utilization of the dynamic capabilities construct, a widely accepted definition has taken long to be developed" (Easterby-Smith, Lyles \& Peteraf, 2008, p. 2). Scholars from varied traditions have viewed 
dynamic capabilities differently depending on their background. Zollo and Winter (2002, p. 339) for example have "defined dynamic capabilities in terms of routines." On the other hand, Eisenhardt and Martin (2000, p. 1105) "have defined dynamic capabilities in terms of processes whose nature varies with the degree of market dynamism taking the form of simple rules in high velocity environments."

The study posits that knowledge and good organizational skills will be developed and deployed after the firm has determined its strategic direction. Such knowledge, which is embedded within the employees in the organizational structure, once implemented will ensure the resources of the firm are exploited to maximum advantage and therefore enable the firm to attain and even sustain a competitive advantage position.

\subsection{The Strategic Planning and Competitive Advantage Model}

The strategic planning and competitive advantage model used in the study is shown in Figure 1. From the model, strategic planning is the independent variable while competitive advantage is the dependent variable. Employee behaviour is the mediating variable while Organizational structure is the moderating variable.

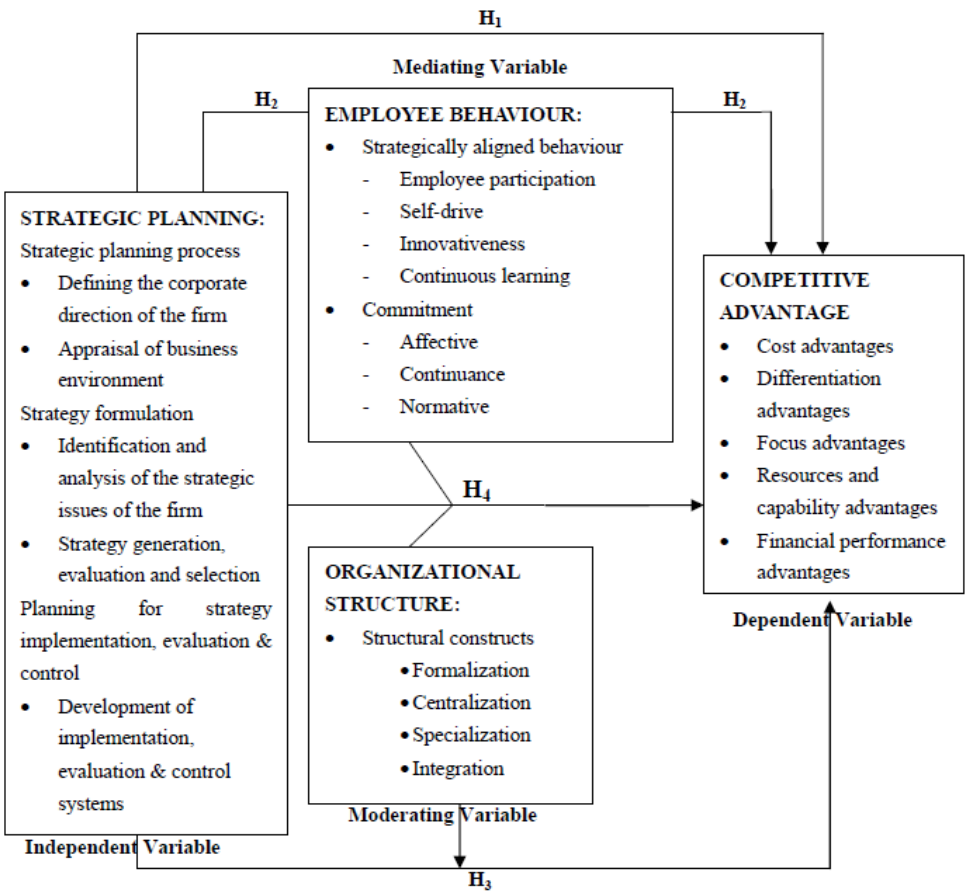

Figure 1. Strategic planning and competitive advantage model

\subsection{Hypotheses of the Study}

From the objectives of the study and through the relationships in the strategic planning and competitive advantage model given in figure 1, the following four hypotheses were formulated for further testing:

$\mathrm{H}_{1}$ - Strategic planning significantly influences the competitive advantage of large manufacturing firms in Kenya.

$\mathrm{H}_{2^{-}}$Employee behaviour significantly influences the relationship between strategic planning and competitive advantage of large manufacturing firms in Kenya.

$\mathrm{H}_{3}$ - Organizational structure significantly affects the relationship between strategic planning and competitive advantage of large manufacturing firms in Kenya.

$\mathrm{H}_{4}$ - The joint influence of employee behaviour and organizational structure is different from the influence of individual variables on the relationship between strategic planning and competitive advantage of large manufacturing firms in Kenya.

\section{Method}

The philosophical foundation of this study was positivism. "By using the positivist paradigm, the researcher was 
guided by objectivity and could not influence the outcome of the study. The researcher was external to the process of collecting data and there was little he could do to alter the substance of the data collected" (Easterby-Smith, Thorpe \& Jackson, 2012, p. 22). This study adopted a descriptive cross-sectional approach in order to establish the link between strategic planning and competitive advantage, the mediating influence of employee behaviour and the moderating effect of organizational structure in large manufacturing firms in Kenya. "A cross-sectional design involves collecting of data on more times than one and at more than one point in time with a view to having an amount of quantitative or qualitative data relating to two or even more than two variables, which are subsequently tested in order to establish any correlation between them" (Bryman \& Bell, 2011, p. 53).

The KAM Directory (2015) had only one measure of categorising manufacturing firms and that is turnover of the firm. Firms with a turnover of between Kshs 50 million and Kshs 150 million were categorised as small in size while firms with a turnover of between Kshs 151 million and Kshs 250 million were categorised as medium in size. Firms with a turnover of over Kshs 251 million were categorized as large in size. The total number of manufacturing firms as per the KAM Directory (2015) excluding the service sector was 604. Out of this total, 299 firms were categorized as small, 181 firms categorized as medium while 124 firms were categorized as large in size. It is these 124 firms which formed the population of interest in this study.

The entire population of 124 large manufacturing companies were studied and therefore no sampling was necessary. The researcher chose a census study because it could enable the study to capture variability of responses. A census study also facilitated comparative analysis and ensured adequate representation, accuracy and reliability. Primary data was collected by using questionnaires while secondary data was extracted from information and documents maintained by the manufacturing firms. Reliability tests were performed to test quality of measurement while "validity tests were undertaken to test the quality of the questionnaire with improvements made where necessary (Sekaran \& Bougie, 2014, p. 225)." In this study, "the Likert-type scale (Saunders, Lewis \& Thornhill, 2012, p. 436) was used and respondents were requested to respond by choosing one option from statements usually given in five degrees of agreement or disagreement."

Collection of data was undertaken between February and May 2018. Out of the 124 firms selected for the study, 122 questionnaires were returned and upon further scrutiny, it was established that all of them had been completed well except in some few instances under the general information section where some respondents had not responded to all the questions. The effective response rate was therefore $98.4 \%$. Out of the 122 respondents, $91.0 \%$ were in top management position while $5.7 \%$ were in middle management. Only $3.3 \%$ of the respondents failed to indicate what their position was. The $98.4 \%$ response rate was good and compared well with other studies on large-scale manufacturing firms in Kenya carried out by other scholars in the past. Awino (2007) achieved a response rate of $65 \%$ and proposed that an average response rate of $65 \%$ for empirical studies is acceptable. Kidombo (2007) achieved a response rate of $64 \%$ while Magutu (2013) had a response rate of $75 \%$.

\section{Results}

The overall objective of the study was to determine whether the relationship between strategic planning and competitive advantage of large manufacturing firms is influenced by employee behaviour and organizational structure. Four hypotheses were set corresponding to the four specific objectives of the study. The results of the four hypotheses starting with hypothesis one $\left(\mathrm{H}_{1}\right)$ are given in the Tables that follow: Table 1 gives the composite results of hypothesis one which states thus:

$\mathrm{H}_{1}$ - Strategic planning significantly influences the competitive advantage of large manufacturing firms in Kenya.

Table 1. Composite influence of strategic planning on overall competitive advantage

\begin{tabular}{llllll}
\hline Model Summary & & & \\
\hline Model & $\mathrm{R}$ & R Square & Adjusted R Square & Std. Error of the Estimate \\
\hline 1 & $.462^{\mathrm{a}}$ & .213 & .207 & .27895 & \\
\hline a. Predictors: (Constant), Strategic planning & & & \\
\hline ANOVA $^{\mathrm{a}}$ & Sum of Squares & df & Mean Square & F & Sig. \\
\hline Model & & & & & \\
\hline
\end{tabular}




\begin{tabular}{|c|c|c|c|c|c|c|c|}
\hline \multirow[t]{3}{*}{1} & Regression & 2.528 & & 1 & 2.528 & 32.490 & $.000^{\mathrm{b}}$ \\
\hline & Residual & 9.338 & & 120 & .078 & & \\
\hline & Total & 11.866 & & 121 & & & \\
\hline \multicolumn{8}{|c|}{ a. Dependent Variable: Competitive advantage } \\
\hline \multicolumn{8}{|c|}{ b. Predictors: (Constant), Strategic planning } \\
\hline \multicolumn{8}{|c|}{ Coefficients $^{\mathrm{a}}$} \\
\hline & & & \multicolumn{2}{|c|}{$\begin{array}{l}\text { Unstandardized } \\
\text { Coefficients }\end{array}$} & $\begin{array}{l}\text { Standardized } \\
\text { Coefficients }\end{array}$ & & \\
\hline \multicolumn{3}{|l|}{ Model } & $\mathrm{B}$ & Std. Error & Beta & $\mathrm{t}$ & Sig. \\
\hline \multirow[b]{2}{*}{1} & (Constant) & & 1.543 & .482 & & 3.200 & .002 \\
\hline & Strategic pla & ng & .636 & .112 & .462 & 5.700 & .000 \\
\hline
\end{tabular}

a. Dependent Variable: Competitive advantage

The results in Table 1 indicate that strategic planning has a moderately weak but positive influence on competitive advantage $(\mathrm{R}=0.462)$. The coefficient of determination was 0.213 and this is an indication that strategic planning explained $21.3 \%$ of the variation in competitive advantage. The remaining $78.7 \%$ is to be explained by other factors not considered in this model.

The ANOVA model had a p-value which was less than 0.05 (p-value $=0.000, \mathrm{~F}=32.490)$, and the results reveal a statistically significant model which implies that strategic planning influences competitive advantage. The results also indicate that strategic planning had a positive contribution with a beta value of 0.462 to a unit change in competitive advantage using the standardized coefficients. The results further indicate statistically significant results with a $\mathrm{p}$-value of 0.000 ( $\mathrm{t}$-value $=5.700$ ) for strategic planning on competitive advantage.

These results confirm hypothesis $\mathrm{H}_{1}$ and lead to the conclusion that strategic planning has a significant influence on competitive advantage. The regression model based on the standardized beta coefficient is fitted thus: $\mathrm{CA}=1.543+0.462 \mathrm{SP}$.

The second hypothesis was stated thus:

$\mathrm{H}_{2}$-Employee behaviour significantly influences the relationship between strategic planning and competitive advantage of large manufacturing firms in Kenya.

Table 2 below summarizes the regression results of the four steps in the mediation process:

Table 2. Summary of combined mediating influence of employee behaviour

\begin{tabular}{|c|c|c|c|c|c|c|c|c|c|c|}
\hline \multirow[b]{2}{*}{ Step } & \multirow{2}{*}{$\begin{array}{l}\text { Variable } \\
\text { Description }\end{array}$} & \multicolumn{2}{|c|}{$\begin{array}{l}\text { Summary } \\
\text { model }\end{array}$} & \multicolumn{2}{|l|}{ ANOVA } & \multicolumn{3}{|c|}{ Coefficients } & \multirow[b]{2}{*}{ t-value } & \multirow[b]{2}{*}{ Sig-p } \\
\hline & & $\mathbf{R}$ & $\mathbf{R}^{2}$ & $\mathbf{F}$ & Sig F & Consta & & Beta & & \\
\hline 1 & SP predicts CA & 0.462 & 0.213 & 32.49 & 0.000 & 1.543 & & 0.462 & 5.700 & 0.000 \\
\hline 2 & SP predicts EB & 0.451 & 0.203 & 30.655 & 0.000 & 1.412 & & 0.451 & 5.537 & 0.000 \\
\hline 3 & EB predicts CA & 0.863 & 0.745 & 350.292 & 0.000 & 0.835 & & 0.863 & 18.716 & 0.000 \\
\hline \multirow{2}{*}{4} & \multirow{2}{*}{$\begin{array}{l}\mathrm{SP} \text { and } \\
\text { predict } \mathrm{CA}\end{array}$} & \multirow{2}{*}{0.867} & \multirow{2}{*}{0.751} & \multirow{2}{*}{179.839} & \multirow{2}{*}{0.000} & \multirow{2}{*}{0.459} & SP & 0.091 & 1.772 & 0.079 \\
\hline & & & & & & & $\mathrm{EB}$ & 0.822 & 16.053 & 0.000 \\
\hline \multicolumn{11}{|c|}{ SP - Composite index of Strategic Planning } \\
\hline \multicolumn{11}{|c|}{ EB - Composite index of Employee Behaviour } \\
\hline A & posite index of & ine & A & & & & & & & \\
\hline
\end{tabular}


According to Baron and Kenny (1986, p. 1177), "mediation can take place in three ways. In order to explain the three ways, we will label the variables as follows: $\mathrm{X}$ will take the place of the independent variable, $\mathrm{M}$ will take the place of the mediating variable while $\mathrm{Y}$, will take the place of the dependent variable. The first rule is on full mediation, and this one takes place when three conditions are met. These conditions are; one, $\mathrm{X}$ predicts $\mathrm{M}$, two, $\mathrm{X}$ predicts $\mathrm{Y}$ and three $\mathrm{X}$ no longer predicts $\mathrm{Y}$, but $\mathrm{M}$ does when both $\mathrm{X}$ and $\mathrm{M}$ are used to predict $\mathrm{Y}$." The second rule is on partial mediation (Baron \& Kenny, 1986, p. 1177). "This takes place when three conditions are met and these conditions are: one $\mathrm{X}$ predicts $\mathrm{M}$, two, $\mathrm{X}$ predicts $\mathrm{Y}$ and three, both $\mathrm{X}$ and $\mathrm{M}$ predict $\mathrm{Y}$, but $\mathrm{X}$ has smaller regression coefficient when both $\mathrm{X}$ and $\mathrm{M}$ are used to predict $\mathrm{Y}$ than when $\mathrm{X}$ only is used. The third decision rule is no mediation taking place at all. This takes place when three conditions are met. The conditions are: one, $\mathrm{X}$ does not predict $\mathrm{M}$, two, $\mathrm{M}$ does not predict $\mathrm{Y}$ and three, the regression coefficient of $\mathrm{X}$ remains the same before and after $\mathrm{M}$ is used to predict Y."

The results in Table 2 indicate that significant results were obtained in steps 1,2 and 3. This means that strategic planning predicts competitive advantage as well as employee behaviour. Besides, employee behaviour predicts competitive advantage and in a very big way as demonstrated by the parameters in Table $2\left(\mathrm{R}^{2}=0.745, \mathrm{~F}=350.292\right.$, sig $\mathrm{F}=0.000$, constant $=0.835$, beta $=0.863$, $\mathrm{t}$-value $=18.716$ and sig $\mathrm{p}=0.000$ ). In step 4 , the last condition is determined by the parameters under the Coefficients section. It is evident that strategic planning is not statistically significant with a p-value of $0.079(\mathrm{t}$-value $=1.772)$ while employee behaviour with a $\mathrm{p}$-value of $0.000(\mathrm{t}$-value $=$ 16.053) is statistically significant. Therefore, step 4 fulfils condition three in the first rule. Because all the three conditions in the first rule are met, therefore employee behaviour completely mediates the strategic planning and competitive advantage relationship.

These results confirm hypothesis $\mathrm{H}_{2}$ and lead to the conclusion that employee behaviour has a significant influence in the relationship between strategic planning and competitive advantage of large manufacturing firms in Kenya.

The third hypothesis was stated thus:

$\mathrm{H}_{3}$-Organizational structure significantly affects the relationship between strategic planning and competitive advantage of large manufacturing firms in Kenya.

To assess the moderating influence of organizational structure on the relationship between strategic planning and competitive advantage, the study used Baron and Kenny (1986) method. Baron and Kenny (1986, p. 1174) posit that "moderation can only be supported if the interaction of the paths of the independent variable and the moderator variable is significant."

Baron and Kenny (1986, p.1174) "proposed three steps be taken when testing for the moderating effect. Step one involves testing the direct effect between the independent and the dependent variable. The results from this first step should be statistically significant for the researcher to proceed to the next step. Step two involves testing the effect of strategic planning and organizational structure on competitive advantage. Step three will involve testing the effect of strategic planning, organizational structure and the interaction term (between strategic planning and organizational structure) on competitive advantage.

The summarized results of the three moderating steps are shown in Table in Table 3 below:

Table 3. Summary of combined moderating effect of organizational structure

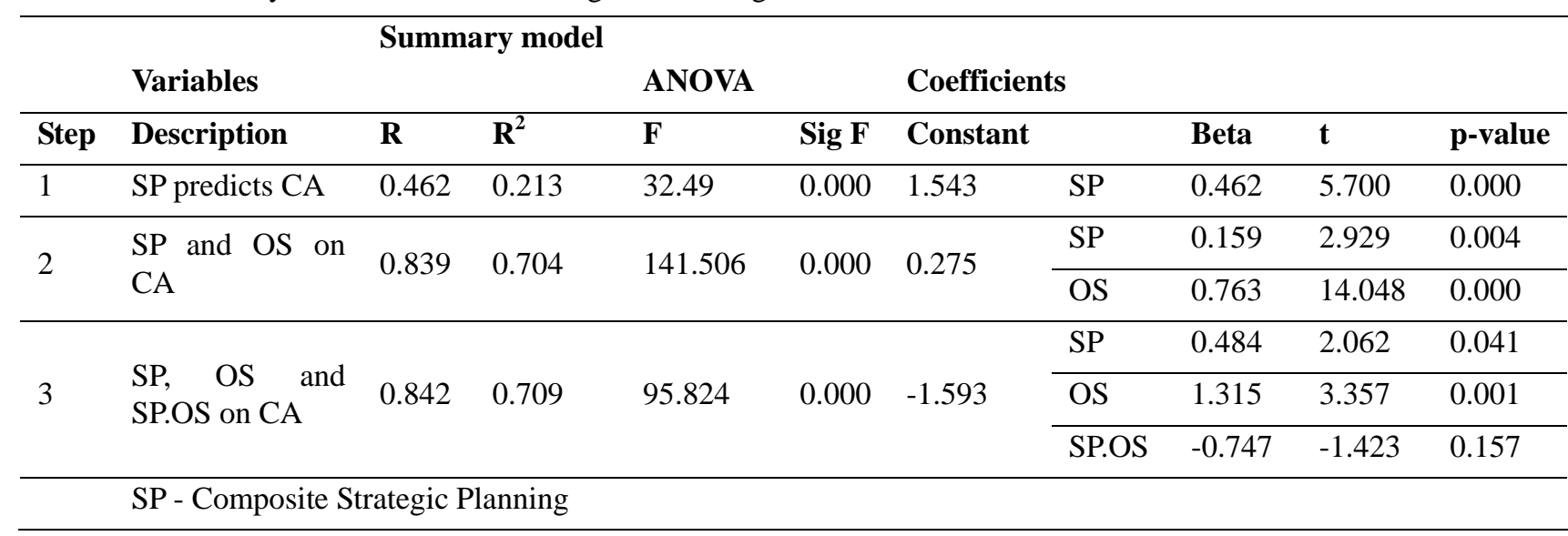


OS - Composite Organizational Structure

SP.OS - Interaction term Strategic Planning X Organizational Structure

CA - Composite Competitive Advantage

Under step one, $\mathrm{R}^{2}$ equals 0.213 indicating that strategic planning explains $21.3 \%$ of the variation in competitive advantage. The overall strength of the model in step one was $0.000(\mathrm{~F}=32.490)$. Furthermore, the p-value at 0.000 $(\mathrm{t}$-value $=5.700)$ indicates significant results.

From step two, it is evident that the combined effects are far higher than for the single effect of strategic planning on competitive advantage. The coefficient of determination $\mathrm{R}^{2}$ for the combined effect is 0.704 implying that both strategic planning and organizational structure can explain $70.4 \%$ of the variation in competitive advantage. The overall strength of the combined model is much stronger with a significance of 0.000 but a very high F-value of 141.506. The beta $(\beta)$ coefficients are also different under the combined value with strategic planning having a beta value of 0.159 while organizational structure has a beta value of 0.763 . Under the combined effect, the results were still statistically significant but had changed for the strategic planning variable. Under step one, the p-value under strategic planning was 0.000 (t-value $=5.700$ ) but in step two, the p-value under strategic planning was 0.004 $(\mathrm{t}$-value $=2.929)$. The $\mathrm{p}$-value for organization structure in step two was $0.000(\mathrm{t}$-value $=14.048)$.

Step three indicates the results after the introduction of the interaction term (SP.OS). The coefficient of determination $\mathrm{R}^{2}$ is higher than in the other two steps at 0.709 indicating that with the interaction term included, $70.9 \%$ of the variation in competitive advantage can be explained. The overall strength of the model remains quite strong with the introduction of the interaction term at a significance $\mathrm{p}=0.000$ and an F-value of 95.824. However, this F-value is lower than in step two where it was 141.506 . The constant term $\left(\beta_{0}\right)$ has also changed into a negative $(-1.593)$ after the introduction of the interaction term. In the first step, the constant factor was 1.543 while in step 2, it was 0.275 .

Both strategic planning and organizational structure have retained their statistically significant results after the introduction of the interaction term at $0.041(\mathrm{t}$-value $=2.062)$ for strategic planning and $0.001(\mathrm{t}$-value $=3.357)$ for organizational structure. However, the interaction term shows non-statistically significant results with a p-value of 0.157 (t-value $=-1.423)$.

There are three decision rules to checking whether moderation has occurred (Baron \& Kenny, 1986, p. 1174). These rules are; "one, after adding the interaction term, if there is a significant change in $\mathrm{R}^{2}$ as well as significant effect by the new interaction term, then moderation is occurring. Decision rule number two is if the predictor and moderator are not significant with the interaction term added, then complete moderation has occurred. Decision rule number three is that if the predictor and moderator are significant with the interaction term added, then moderation has occurred, however, the main effects are also significant."

In the study model, there was a significant change in $\mathrm{R}^{2}$ as compared to the first step, but the change was not as big as compared to the second step (with interaction term, $\mathrm{R}^{2}$ was 0.709 , while under step one, $\mathrm{R}^{2}$ was 0.213 and in step two, $\mathrm{R}^{2}$ was 0.704$)$. After the introduction of the interaction term, there was a significant change in the F-value (95.824 with interaction term, 141.506 with the predictor [SP] and moderator [OS] and 32.49 with strategic planning only). This implies that the first condition for a moderation effect to exist was met. The other condition which has been met is the third one. Under this condition, the predictor (SP) and moderator (OS) have to be significant with the interaction term added and the main effects are also significant. Strategic planning produced statistically significant results with a $\mathrm{p}$-value of 0.041 ( $\mathrm{t}$-value $=2.062)$ while organizational structure had a $\mathrm{p}$-value of $0.001(\mathrm{t}$-value $=$ 3.357). The interaction term produced statistically non-significant results with a $\mathrm{p}$-value of 0.157 (t-value $=-1.423$ ).

The overall results from hypothesis three were therefore that partial moderation had taken place. These findings were sufficient to support the hypothesis $\mathrm{H}_{3}$, which states that, organizational structure significantly affects the relationship between strategic planning and competitive advantage of large manufacturing firms in Kenya.

The fourth hypothesis was stated thus:

$\mathrm{H}_{4}$-The joint influence of employee behaviour and organizational structure is different from the influence of individual variables on the relationship between strategic planning and competitive advantage of large manufacturing firms in Kenya.

Table 4 below shows the individual effects of strategic planning, employee behaviour and organizational structure on competitive advantage as compared with the overall influence of the three variables on competitive advantage. 
Table 4. Summary of the sum total of the influence of the three variables on competitive advantage

\begin{tabular}{llllllll}
\hline Variable relationship & $\mathbf{R}$ & $\mathbf{R}^{\mathbf{2}}$ & $\mathbf{F}$ & $\mathbf{F}$ - sig & $\mathbf{t}$ & & p-value \\
\hline Strategic planning (SP) on CA & 0.462 & 0.213 & 32.490 & 0.000 & 5.700 & 0.000 \\
\hline Employee behaviour (EB) on CA & 0.863 & 0.745 & 350.292 & 0.000 & 18.716 & 0.000 \\
\hline Organizational structure (OS) on CA & 0.826 & 0.683 & 258.122 & 0.000 & & 16.066 & 0.000 \\
\hline Total & $\mathbf{2 . 1 5 1}$ & $\mathbf{1 . 6 4 1}$ & $\mathbf{6 4 0 . 9 0 4}$ & & & & \\
\hline & & & & & SP & 1.617 & 0.109 \\
\cline { 6 - 8 } Joint effect of SP, EB and OS on CA & $\mathbf{0 . 8 9 4}$ & $\mathbf{0 . 8 0 0}$ & $\mathbf{1 5 6 . 8 5 7}$ & 0.000 & EB & 7.498 & 0.000 \\
\cline { 5 - 8 } & & & & & OS & 5.322 & 0.000 \\
\hline
\end{tabular}

Table 5. Joint influence of strategic planning, employee behaviour and organizational structure on competitive advantage (coefficients section)

\begin{tabular}{|c|c|c|c|c|c|c|}
\hline \multicolumn{7}{|c|}{ Coefficients $^{\mathrm{a}}$} \\
\hline \multirow[b]{3}{*}{ Model } & & \multirow{2}{*}{\multicolumn{2}{|c|}{$\begin{array}{l}\text { Unstandardized } \\
\text { Coefficients }\end{array}$}} & \multirow{3}{*}{$\begin{array}{l}\text { Standardized } \\
\text { Coefficients } \\
\text { Beta }\end{array}$} & \multirow[b]{3}{*}{$\mathrm{t}$} & \multirow[b]{3}{*}{ Sig. } \\
\hline & & & & & & \\
\hline & & B & Std. Error & & & \\
\hline \multirow[t]{4}{*}{1} & (Constant) & .227 & .257 & & .885 & .378 \\
\hline & Strategic Planning & .103 & .064 & .075 & 1.617 & .109 \\
\hline & Employee Behaviour & 498 & 066 & .534 & 7.498 & .000 \\
\hline & Organizational Structure & .349 & .065 & .368 & 5.322 & .000 \\
\hline
\end{tabular}

a. Dependent Variable: Competitive Advantage

The results in Table 4 indicate statistically significant results for the individual influence of strategic planning, employee behaviour and organizational structure at p-values of 0.000 for all the three variables respectively. On the joint effect of the three variables on competitive advantage, strategic planning turns out non-significant results with a $\mathrm{p}$-value of $0.109(\mathrm{t}$-value $=1.617)$ while employee behaviour has significant results with a $\mathrm{p}$-value of $0.000(\mathrm{t}$-value $=$ 7.498 ) and organizational structure also has significant results with a p-value of 0.000 ( $\mathrm{t}$-value $=5.322$ ).

The variable that explains the biggest variation of competitive advantage on its own is employee behaviour, explaining $74.5 \%$. This is followed by organizational structure, which explains $68.3 \%$, strategic planning explains only $21.3 \%$ of competitive advantage. The three variables jointly explain $80.0 \%$ of the variation in competitive advantage.

When the $\mathrm{R}^{2}$ of the three variables, that is, strategic planning, employee behaviour and organizational structure are added together, the total is 1.641 . This would imply that if their effect on competitive advantage could be taken sequentially, that is, one variable after the other, they would explain 1.641 of the variation in competitive advantage.

The stepwise multiple regression analysis has two steps. Step one is on the influence of the independent variable, strategic planning, on competitive advantage. The $\mathrm{R}^{2}$ under this step was $21.3 \%$. Step two was on the joint effect of the three variables, strategic planning, employee behaviour and organizational structure on competitive advantage. The $\mathrm{R}^{2}$ on the joint effect was $80.0 \%$.

The overall strength of the model in step one was 0.000 but with an F distribution value of 32.490 while under step two, the strength of the model was still 0.000 with an F distribution value of 156.857. The models under steps one and two were different. Based on these results, the regression model under step one is fitted thus: $\mathrm{CA}=1.543+0.462 \mathrm{SP}$ (from Table 1); while under step two, the regression model is: $\mathrm{CA}^{1}=0.227+0.075 \mathrm{SP}^{1}+0.534 \mathrm{~EB}^{1}+0.368 \mathrm{OS}^{1}$ (from Table 5)

From the foregoing, the findings were sufficient to support hypothesis $\mathrm{H}_{4}$, which states that, the joint influence of employee behaviour and organizational structure is different from the influence of individual variables on the relationship between strategic planning and competitive advantage of large manufacturing firms in Kenya. 


\section{Discussion of Results and Conclusion}

The overall objective of the study was to determine whether the relationship between strategic planning and competitive advantage of large manufacturing firms in Kenya is influenced by employee behaviour and organizational structure. A model was developed to empirically test these relationships. This was a census study and data was collected from senior managers (top managers) in the 124 large manufacturing firms in Kenya as per the KAM Directory (2015) in order to test the model that had been developed.

Four specific objectives had been formulated to test the relationships between the four variables. Against the four specific objectives were developed four hypotheses for further testing. The results indicated a statistically significant relationship on the first hypothesis which stated that strategic planning influenced the competitive advantage of large manufacturing companies in Kenya. On the second hypothesis that was testing whether employee behaviour influenced the relationship between strategic planning and competitive advantage of large manufacturing firms in Kenya, the results were statistically significant. It was established that employee behaviour completely mediates the relationship between strategic planning and competitive advantage. The third hypothesis was on whether organizational structure affected the relationship between strategic planning and competitive advantage of large manufacturing firms in Kenya. Partial moderation of the relationship between strategic planning and competitive advantage by organizational structure was established, and therefore the third hypothesis was confirmed.

The fourth hypothesis was on whether the joint influence of employee behaviour and organizational structure was different from the influence of individual variables on the relationship between strategic planning and competitive advantage. This hypothesis was confirmed. It was established that the influence of strategic planning on competitive advantage was different from the joint effects of the three variables on competitive advantage.

The results of the study contributed to strengthening the existing body of literature confirming empirically that strategic planning influences competitive advantage of large manufacturing firms both directly and indirectly through the mediating and moderating variables. The anchoring theory/typology of Michael Porter's competitive advantage (1990) was confirmed. Porter (1990) has argued that the foundation for above average performance within an industry is sustainable competitive advantage, which can be achived through cost leadership, differentiation or focus. "Goal setting theory (Locke \& Latham, 1990; 2002, p. 705) was used to support employee behaviour. In their studies, Locke and Latham (1990, 2002, p. 705), found that specific high goals led to a higher level of task performance than do easy goals or vague, abstract goals." This is as long as a person is committed to the goal, has the requisite ability to attain it, and does not have conflicting goals." The contingency theory was used to support organizational structure. The theory is founded on the presumption that there is no one form of organizational structure which can be applied to different types of organizations (Van de Ven \& Drazin, 1985). Instead, how effective an organization is depends on a fit between the technology use, its information system, the volatility of the environment, the organization size and the components of the organizational structure.

These findings inform the senior managers of large manufacturing firms that they need to focus on the three study variables if they have to influence competitive advantage and ultimately the performance of their firms significantly. The study established that the joint effect of the three variables, strategic planning, employee behaviour and organizational structure explains $80.0 \%$ of the variation in competitive advantage. This implies that senior managers of large manufacturing firms would be losing quite a large portion of what would generate competitive advantage if they ignored the three variables.

It was established that strategic planning, employee behaviour and organizational structure independently contribute more to competitive advantage than the joint effects of the variables. It can be argued that the independent effects of the variables influence firm's competitive advantage by creating synergy. In effect, no single variable can effectively influence the competitive advantage of a firm. The study has attempted to establish the synergistic effect of the study variables to create competitive advantage. This conclusion is consistent with findings from previous research and lends credence to the fact that the performance of a firm is determined, in part, by the combination of factors from both the external environment and internal capabilities.

The foregoing conclusions notwithstanding, the study lacked comparison of other similar studies done either locally or abroad. It was therefore difficult to generalize on the study findings. Besides, the study utilized a cross-sectional survey because it was the most appropriate at the time. Cross-sectional studies however, do not allow for causal effects on the observed relationships over time and therefore could not give actual relationships that exist between strategic planning, employee behaviour, organizational structure and competitive advantage of large manufacturing firms in Kenya. Future researchers could consider using approaches like longitudinal studies. Such studies can give the change in competitive advantage of large manufacturing firms over time. The study was designed to capture the 
response of one respondent per firm at a given point in time. Using a single respondent for research has limitations because of the possibility of the common method bias. Although the respondents are thought and expected to give objective responses, they could have their own biases and perceptions, which could lead to misleading and subjective responses. It therefore becomes difficult to tell whether the perception was the respondent's or the organization's. Future researchers could consider using multiple respondents in order to compare views of other respondents in the firm.

The study focused on large manufacturing firms and did not consider small and medium-sized manufacturing firms. The small to medium-sized manufacturing firms may be faced with different challenges as compared to large manufacturing firms. It may therefore be difficult to generalize the results obtained from the large manufacturing firms to the small to medium-sized firms. The study was also focussed on the manufacturing sector, which mainly deals in goods. Similar studies could be carried out on the small to medium-sized manufacturing firms as well as in other sectors of the economy including banks and insurance companies.

Finally, the study operationalized competitive advantage on five perspectives of cost advantages, differentiation advantages, focus advantages, resources and capability advantages and financial performance advantages. These indicators are highly business specific. The study did not consider environmental and social aspects as indicators. These could cover areas like legality and freedom of action among others, which are exposures on environmental and social nature. Future studies could consider including environmental and social aspects as indicators of competitive advantage.

\section{Acknowledgements}

I wish to convey my special sincere gratitude to my supervisors, Prof. Zachary B. Awino, Prof. Peter O. K'Obonyo and Prof. Ganesh P. Pokhariyal for their tremendous support, guidance and encouragement as I did this study. I would like to thank them for being patient with me during the many hours of consulting them that enabled me to reach the final stages of the program. The many hours they spent critiquing, correcting and giving me wise counsel on how to proceed have enabled me to get this far. My supervisors were truly patient with me and I would like to thank them very much.

\section{References}

Awino, Z. B. (2007). Strategic management: An empirical investigation of selected strategy variables on firm performance: a study of supply chain management in large private manufacturing firms in Kenya. Prime Journals, 1(1), 9-18.

Awino, Z. B. (2013). Strategic planning and competitive advantage of ICT small and medium enterprises in Kenya. Business and Management Horizons, 1(1), 191-204. https://doi.org/10.5296/bmh.v1i1.3942

Barney, J. B. (1991). Firm resources and sustained competitive advantage. Journal of Management, 17(1), 99-120. https://doi.org/10.1177/014920639101700108

Barney, J., \& Hesterly, W. (2012). Strategic Management and Competitive Advantage: Concepts and cases (4th ed.). New Jersey: Pearson.

Baron, R. M., \& Kenny, D. A. (1986). The moderator-mediator variable distinction social psychological research: Conceptual, strategic and statistical considerations. Journal of Personality and Social Psychology, 51, 1173-1182. https://doi.org/10.1037/0022-3514.51.6.1173

Barsky, A. (2007). Understanding the ethical cost of organizational goal-setting: a review and theory development. Journal of Business Ethics, 81(1), 63-81. https://doi.org/10.1007/s10551-007-9481-6

Bazerman, M. H., \& Chugh, D. (2006). Decisions without Blinders. Harvard Business Review, 84(1), 88-97.

Bryman, A., \& Bell, E. (2011). Business Research Methods (3rd ed.). Oxford University Press. Great Clarendon Street, Oxford.

Cees, B. M., Van, R., Guido, B., \& Majorie, D. (2009). Stimulating strategically aligned behaviour among employees. Journal of Management Studies, 46, 1197-1226. https://doi.org/10.1111/j.1467-6486.2009.00837.x

Chavunduka, D., Chimunhu, P., \& Sifie, O. (2015). Strategic Planning intensity and firm performance: A case of Zimbabwe mining development corporation. European Journey of Business and Management, 7(5), 12-18.

Dirisu, J. I., Iyiola, O., \& Ibidunni, O. S. (2013). Product differentiation: a tool of competitive advantage and optimal organizational performance (a study of Unilever Nigeria PLC). European Scientific Journal, 9(34), 258-281. 
Easterby-Smith, M., Iyles, P., \& Peteraf, M. (2008). Dynamic capabilities: current debates and future directions. British Journal of Management, 609, 1-8.

Easterby-Smith, M., Thorpe, R., \& Jackson, P. (2012). Management Research (4th ed.). SAGE Publications Ltd., London.

Eisenhardt, K. M., \& Martin, J. A. (2000). Dynamic capabilities: what are they?. Strategic Management Journal, 21, 1105-1121. https://doi.org/10.1002/1097-0266(200010/11)21:10/11<1105::AID-SMJ133>3.0.CO;2-E

Flamholtz, E., \& Hua, W. (2010). Searching for competitive advantage in the black box. European Management Journal, 21(2), 222-236. https://doi.org/10.1016/S0263-2373(03)00017-3

Godfrey, P. C., \& Hill, C. W. L. (1995). The problem of unobservables in strategic management research. Strategic Management Journal, 16, 519-533. https://doi.org/10.1002/smj.4250160703

Gowrie, V., Sreenivasan, J., \& Govindan, M. (2012). Critical success factors of sustainable competitive advantage; a study in Malaysian manufacturing industries. International Journal of Business and Management, 7(22), 29-45.

Hamel, G., \& Prahalad, C. (1994). Competing for the Future. Harvard University Press, Boston.

Kenya Association of Manufacturers. (2015). The Kenya Association of Manufacturers and Exporters Directory Nairobi. Adafric Communications Limited.

Kidombo, H. J. (2007). Human resource strategic orientation, firm's commitment and firm performance in large private manufacturing firms in Kenya. Unpublished PhD Thesis, University of Nairobi, Nairobi.

Kumar, P. (2015). Correlation between strategic planning and firm performance. International Journal of Management and Business Studies, 5(2), 64-75.

Locke, E. A., \& Latham, G. P. (1990). A Theory of Goal Setting and task Performance. Engelwood Cliffs, NJ: Prentice-Hall.

Locke, E. A., \& Latham, G. P. (2002). Building a practically useful theory of goal setting and task motivation: a 35-year odyssey. American Psychologist, 57(9), 705-717. https://doi.org/10.1037/0003-066X.57.9.705

Magutu, P. O. (2013). Supply Chain Strategies, Technology and Performance of Large Scale Manufacturing Firms in Kenya. Unpublished PhD Thesis, University of Nairobi, Kenya.

Manar, I. A. (2014). The impact of organizational structure on organizational commitment: a comparison between public and private sector firms in Jordan. European Journal of Business Management, 6(12), 30-37.

Mathieu, J. E., \& Zajac, D. (1990). A review and meta-analysis of the antecedents, correlates, and consequences of organizational commitment. Psychological Bulletin, 108, 171-194. https://doi.org/10.1037/0033-2909.108.2.171

Molloy, J., Chadwick, C., Ployhart, R., \& Golden, S. (2011). Making intangibles tangible. A multidisciplinary critique and validation framework. Journal of Management, 37, $1496-1518$. https://doi.org/10.1177/0149206310394185

Mowday, R. T., Porter, L. W., \& Steers, R. M. (1982). Employee-organization linkage: The Psychology of Commitment, Absenteeism and Turnover. New York, Academic Press.

Mutunga, S. L., \& Minja, D. (2014). Generic strategies employed by food and beverage firms in Kenya and their effects on sustainable competitive advantage. International Journal of Business and Management Review, 2(6), $1-15$.

Neale, M. A., \& Bazerman, M. H. (1985). The effects of externally set goals on reaching integrative agreements in competitive markets. Journal of Occupational Behaviour, 6(1), 19-32. https://doi.org/10.1002/job.4030060103

Peteraf, M. (1993). The cornerstone of competitive advantage: A resource-based view. Strategic Management Journal, 14, 179-191. https://doi.org/10.1002/smj.4250140303

Peteraf, M., \& Barney, J. (2003). Unravelling the resource-based tangle. Managerial and Decision Economics, 24(4), 309-323. https://doi.org/10.1002/mde.1126

Pfeffer, J. (1994). Competitive Advantages Through People. Boston, M.A: Havard Business School Press.

Porter, M. E. (1980). Competitive Strategy: Techniques for Analyzing Industries and Competitors. New York: The Free Press.

Porter, M. E. (1990). The Competitive Advantage of the Nations. New York: Free Press. 
https://doi.org/10.1007/978-1-349-11336-1

Rawsthorne, L. J., \& Elliot, A. J. (1999). Achievement goals and intrinsic motivation: A meta-analytic review. Personality and Social Psychology Review, 3(4), 326-344. https://doi.org/10.1207/s15327957pspr0304_3

Rumelt, R. P (1984). Towards a strategic theory of the firm. In R. Lamb (Ed.), Competitive Strategic Management (pp. 556-570). Eaglewood Cliffs, NJ: Prentice-Hall.

Saunders, M., Lewis, P., \& Thornhill, A. (2012). Research Methods for Business Students (6th ed.). Harlow: Prentice Hall, Pearson Education Limited.

Schweitzer, M. E., Ordonez, L., \& Douma, B. (2004). Goal-setting as a motivator of unethical behaviour. Academy of Management Journal, 47(3), 422-432.

Sekaran, U., \& Bougie, R. (2014). Research Methods for Business: A Skill-Building Approach (6th ed.). John Wiley $\&$ Sons Ltd.

Teece, D. J., Pisano, G., \& Shuen, A. (1997). Dynamic capabilities and strategic management. Strategic Management Journal, $18(7)$,

509-533. https://doi.org/10.1002/(SICI)1097-0266(199708)18:7<509::AID-SMJ882>3.0.CO;2-Z

Van de Ven, A. H., \& Drazin, R. (1985). The concept of fit in contingency theory. Research in Organizational Behaviour, 7(4), 333-365.

Wernerfelt, B. (1984). The resource-based view of the firm. Strategic Management Journal, 5(2), 171-180. https://doi.org/10.1002/smj.4250050207

Wood, R., Bandura, A., \& Bailey, T. (1990). Mechanisms governing organizational performance in complex decision-making environments. Organizational Behaviour and Human Decision Processes, 46(2), 181-201. https://doi.org/10.1016/0749-5978(90)90028-8

Yearta, S. K., Maitlis, S., \& Briner, R. B. (1995). An exploratory goal-setting in theory and practice: a motivational technique that works. Journal of Occupational and Organizational Psychology, 68, 237-252. https://doi.org/10.1111/j.2044-8325.1995.tb00584.x

Zollo, M., \& Winter, S. (2002). Deliberate learning and the evolution of dynamic capabilities. Organization Science, 13, 339-351. https://doi.org/10.1287/orsc.13.3.339.2780 